\title{
Sleep duration, cardiovascular disease, and proinflammatory biomarkers
}

This article was published in the following Dove Press journal:

Nature and Science of Sleep

20 July 2013

Number of times this article has been viewed

\author{
Michael A Grandner ${ }^{1,2}$ \\ Megan R Sands-Lincoln ${ }^{3}$ \\ Victoria M Pak ${ }^{2,4}$ \\ Sheila N Garland 1,5
}

'Behavioral Sleep Medicine Program, Department of Psychiatry, Perelman School of Medicine, University of Pennsylvania, PA, USA; ${ }^{2}$ Center for Sleep and Circadian Neurobiology, University of Pennsylvania, PA, USA; ${ }^{3}$ Center for Evidence Based Medicine, Elsevier Inc, Philadelphia, PA, USA; ${ }^{4}$ Division of Sleep Medicine, Perelman School of Medicine, University of Pennsylvania, PA, USA; ${ }^{5}$ Department of Family Medicine and Community Health, Perelman School of Medicine, University of Pennsylvania, PA, USA

Correspondence: Michael A Grandner Center for Sleep and Circadian Neurobiology, University of Pennsylvania, 3624 Market Street, Suite 205,

Philadelphia, PA 19104, USA

Tel + I 2156151756

$\mathrm{Fax}+|21570| 183 \mid$

Email grandner@upenn.edu

\begin{abstract}
Habitual sleep duration has been associated with cardiometabolic disease, via several mechanistic pathways, but few have been thoroughly explored. One hypothesis is that short and/or long sleep duration is associated with a proinflammatory state, which could increase risk for cardiovascular and metabolic diseases. This hypothesis has been largely explored in the context of experimental sleep deprivation studies which have attempted to demonstrate changes in proinflammatory markers following acute sleep loss in the laboratory. Despite the controlled environment available in these studies, samples tend to lack generalization to the population at large and acute sleep deprivation may not be a perfect analog for short sleep. To address these limitations, population based studies have explored associations between proinflammatory markers and habitual sleep duration. This review summarizes what is known from experimental and cross-sectional studies about the association between sleep duration, cardiovascular disease, and proinflammatory biomarkers. First, the association between sleep duration with both morbidity and mortality, with a focus on cardiovascular disease, is reviewed. Then, a brief review of the potential role of proinflammatory markers in cardiovascular disease is presented. The majority of this review details specific findings related to specific molecules, including tumor necrosis factor- $\alpha$, interleukins-1, -6 , and -17 , $\mathrm{C}$-reactive protein, coagulation molecules, cellular adhesion molecules, and visfatin. Finally, a discussion of the limitations of current studies and future directions is provided.
\end{abstract}

Keywords: sleep duration, inflammation, cardiovascular disease, cytokines

\section{Introduction}

Sleep duration has been identified as a risk factor for cardiometabolic disease and mortality. Many adverse outcomes, including those in the cardiometabolic domain, have been associated with both short ${ }^{1,2}$ and long ${ }^{3,4}$ sleep duration. Sleep has an important role in immunity, especially in the context of disease, ${ }^{5-7}$ but the question remains as to whether this translates to more systemic relationships, ie, whether habitual sleep patterns influence the underlying physiology of the immune system in such a way that it predisposes individuals to cardiometabolic disease. ${ }^{8-10}$ One potential pathway linking sleep duration and cardiometabolic health is via systemic inflammation. Although inflammation can be difficult to reliably measure and may be confounded by a number of other influences, it remains as one of the most promising mechanistic links between sleep and cardiometabolic health.

Using PubMed, articles were identified that included the terms "sleep duration," or "short sleep," or "long sleep," or "sleep restriction," or "sleep deprivation," and “inflammation," or "inflammatory," or “cytokine," or "immune”. Abstracts were 
scanned and eligible articles were read in full. Reference sections were scanned for additional articles. All studies that examined habitual sleep duration were included. Studies that examined sleep restriction were also included if the hypotheses of these studies were not examined in any studies of sleep duration. Studies of total sleep deprivation were included only if no other data were available. Using these criteria, the present review identified several proinflammatory biomarkers that have been studied in relation to sleep duration or sleep deprivation, including tumor necrosis factor (TNF)- $\alpha$, interleukins (ILs)-1, -6, and -17, C-reactive protein (CRP), coagulation molecules, cellular adhesion molecules, and visfatin.

\section{Issues with the existing literature}

Several issues emerged upon review of the literature. Although these are described in detail in the "Limitations of existing studies" section below, some are important to note prior to the literature review. First, there was inconsistent use of terms across studies. Often, in both the popular press and scientific literature, "short sleep duration" is often conflated with a number of other terms and concepts such as "sleep loss," "insufficient sleep," "sleep deprivation," "sleep disturbance," etc. Although these are all distinct terms with different meanings, they are often used interchangeably. To improve specificity, authors need to be cautious and judicious regarding their use of these terms. Suggested definitions of specific terms have been outlined previously, ${ }^{1}$ but will be briefly described for the purposes of this review. Short sleep duration, or short habitual sleep duration, reflects retrospective or prospective assessments of what is purported to be habitual sleep duration in real world settings. Sleep deprivation and sleep restriction refers to forced reduction in sleep time in acute situations. In the case of total sleep deprivation, this refers to complete lack of sleep over one or more nights; in the case of partial sleep deprivation or sleep restriction, this refers to the reduction (but not elimination) of allowed sleep time in the laboratory. In this review, the definition of short sleep and sleep restriction, in terms of allowed, reported, or demonstrated duration, will be specified.

As a consequence of the various definitions of the exposure of interest, sleep duration studies are difficult to compare in aggregate. Setting aside issues of differing methodology addressed above, sleep duration is often assessed categorically. In population studies, sleep is typically categorized as "short" based on a cutoff of $<5,<6$, or $<7$ hours duration, or some other definition. In sleep restriction studies, this is usually determined by group or condition where certain allowed time in bed is enforced. Usually the control condition is $8-10$ hours in bed and the intervention is 4-6 hours in bed, depending on the study. Again, since there are no standard definitions that apply to all studies, the exact exposure will need to be specified.

The problem with defining terms speaks to a broader issue - if the goal of this review is to describe sleep duration studies (to generalize to real world situations), why are studies of sleep deprivation and sleep restriction included at all? The primary reason is that there are still very few studies of habitual sleep duration relative to inflammation. The inclusion of sleep restriction studies is intended to suggest other associations that may exist and that have not yet been tested at the population level. Also, where there is an absence of population level and sleep restriction data, studies incorporating total sleep deprivation have been included. It should be noted, however, that total sleep deprivation often does not produce similar physiologic outcomes to sleep restriction or reduced sleep duration, although it may suggest regulatory functions of sleep in these systems.

In addition, many studies that evaluate sleep duration groups combine a number of possible durations (eg, short sleepers represented as $<6$ hours in many cases $)^{1}$ and the definitions of groups are often inconsistent. At times, sleep duration is treated as a continuous variable, while in other studies, groups are compared relative to a specified sleep duration comparator (eg, 7 hours). Also, as mentioned above, both short and long sleeps have been variously defined. This variability in group definitions limits generalization across studies. Other issues, described in more detail below, include insufficient sample size, insufficient stratification, floor effects, and other factors.

\section{Sleep duration associated with morbidity and mortality Sleep duration and mortality}

Over 40 years of evidence indicates a strong association between nightly sleep duration and mortality risk. ${ }^{3,4}$ Overall, sleep duration is associated with mortality in a U-shaped fashion, with the highest risk found for short and long sleepers and the lowest risk in individuals who report average sleep durations of 7-8 hours. The first study to examine the relationship between sleep duration and mortality risk in the population was reported among US residents in 1964, over a 3-year follow-up period. ${ }^{11}$ Those reporting 7 hours of sleep demonstrated the lowest mortality rate. A follow-up analysis of the same sample population ${ }^{12}$ found that 7-hour 
sleepers had the lowest risk, and those at the extreme ends ( $\leq 4$ and $\geq 10$ hours) had the highest risk for both men and women. A series of subsequent investigations analyzed data from adults from the Alameda County Study, ${ }^{13-17}$ finding that short ( $\leq 6$ hours) and long ( $\geq 9$ hours) sleepers had higher mortality rates than 7-8 hour sleepers, even after adjustment for covariates. In elderly subjects, increased mortality has been associated more with long, ${ }^{18-20}$ versus short, ${ }^{18}$ sleep durations, although not all studies found significant associations. ${ }^{21,22}$ Studies replicating significant associations between sleep duration and mortality risk have been conducted in Japan, ${ }^{23-27}$ Taiwan, ${ }^{28}$ Singapore, ${ }^{29}$ Israel, ${ }^{30}$ Sweden, ${ }^{31}$ Finland, ${ }^{32}$ Brazil, ${ }^{33}$ the UK, ${ }^{34-36}$ and the US. ${ }^{37-43}$

Gallicchio and Kalesan ${ }^{44}$ conducted a meta-analysis of 23 studies investigating the association between sleep duration and mortality conducted from 1979 to 2007 . Using random effects meta-analysis, the authors report that the pooled relative risk (RR) for all cause mortality for short sleep was 1.10 (95\% confidence interval [CI] 1.06-1.15), with cardiovascular related RR at 1.06 (95\% CI 0.94-1.30) and cancer related RR at 0.99 (95\% CI 0.88-1.13). For long sleep, RR for all cause mortality was $1.23(95 \%$ CI 1.16-1.30), with cardiovascular RR at 1.38 (95\% CI 1.13-1.69) and cancer RR at 1.21 (95\% CI 1.11-1.32). Thus, while short sleep carries an increased mortality risk, this is not explained by cardiovascular disease (CVD) or cancer. For long sleep, the increased risk was significant for all cause, cancer, and cardiovascular mortality. In a more recent metaanalysis including 16 published studies from 1993 to 2009 , Cappuccio et al examined whether evidence supported the presence of a relationship between duration of sleep and all cause mortality and to obtain an estimate of the risk. ${ }^{45}$ This meta-analysis demonstrated similar effects, including a RR of 1.12 (95\% CI 1.06-1.18) for short sleep and RR of 1.30 (95\% CI 1.22-1.38) for long sleep.

Taken together, these individual and population based studies, narrative reviews, and meta-analyses, suggest that habitual sleep duration is associated with mortality. Specifically, both short and long sleep duration are associated with elevated risk, albeit through potentially different mechanisms..$^{1,46-48}$ The exact pathways by which this risk is conferred are not well known.

\section{Sleep duration and CVD risk}

CVDs account for approximately $25 \%$ of all US deaths and are the leading cause of death in both men and women. ${ }^{49}$ Coronary heart disease (CHD) and stroke account for the highest percentage of these deaths, followed by high blood pressure and diabetes. Well established behavioral risk factors for CVD include an unhealthy diet, physical inactivity, and tobacco and alcohol use, ${ }^{50}$ however, recent evidence suggests that sleep duration may be an additional modifiable behavior to further reduce cardiovascular risk. Hoevenaar-Blom et $\mathrm{al}^{51}$ conducted a 12 -year prospective study of 20,432 men and women in The Netherlands with no history of CVD to investigate the association between short and long sleep duration with total CVD and CHD incidence, independent of other modifiable lifestyle factors. Compared to people who slept 7-8 hours, short sleepers (defined as those individuals who slept $\leq 6$ hours) had a $15 \%$ higher risk of total CVD incidence (hazard ratio [HR] of $1.15 ; 95 \%$ CI $1.00-1.32$ ) and a $23 \%$ higher risk of CHD incidence (HR of 1.23; 95\% CI 1.04-1.45). An association between long sleepers (defined as those individuals who slept $\geq 9$ hours) was not found with CVD risk (HR of $0.94 ; 95 \%$ CI $0.76-1.16$ ). It also appears that the quality of sleep for those people sleeping $\leq 6$ hours adds additional risk for CVD. When compared to individuals with normal sleep duration and good sleep quality, short sleepers with poor subjective sleep had a $63 \%$ higher risk of CVD (HR of 1.63 ; 95\% CI 1.21-2.19) and a 79\% higher risk of CHD incidence (HR of 1.79; 95\% CI 1.24-2.58). These findings add to past cross-sectional and population based research demonstrating the association between short sleep duration and increased CVD risk. ${ }^{52,53}$

The role of short sleep in predicting CVD risk has also been cumulatively validated by meta-analysis ${ }^{54}$ to the extent that sleep duration can no longer be overlooked as a potentially modifiable risk factor for CVD risk. In a review of 15 studies including 474,684 male and female participants, Cappuccio et $\mathrm{al}^{54}$ found that short sleep (defined as $\leq 5-6$ hours) was associated with a RR of 1.48 (95\% CI $1.22-1.80)$ and long sleep (defined as >8-9 hours) was associated with a RR of 1.38 (95\% CI 1.15-1.66) of dying or developing CHD. Similarly, the RR for developing or dying from stroke was 1.15 (95\% CI 1.00-1.31) for short sleep and 1.65 (95\% CI 1.45-1.87) for long sleep. When overall CVD risk was assessed, short sleep was not a significant risk factor (RR of 1.03) but long sleep was associated with a $41 \%$ increased risk of developing or dying from CVD (RR of 1.41 ; 95\% CI 1.19-1.68).

Despite the strong evidence for sleep duration (both short and long) as a risk factor for CVD risk, we still do not fully understand the mechanisms of this association. It may be important to consider long sleep and short sleep as two potentially different risk factors mediated by separate 
pathways. Cappuccio et al suggested that short sleep duration may be related to negative cardiovascular outcomes via (1) changes in ghrelin/leptin production leading to increased caloric intake, obesity, and impaired glycemic control, and (2) increased secretion of the stress hormone cortisol and altered growth hormone production. ${ }^{54}$ It is also possible that short sleep alone causes sufficient low grade inflammation making it a risk factor for not only CVD but also for other chronic conditions, such as cancer. In contrast, Cappuccio et al suggested that factors such as unemployment, low socioeconomic status, and undiagnosed health conditions may confound the association between long sleep and cardiovascular morbidity and mortality. ${ }^{54}$

\section{Sleep duration and health: a public health imperative}

Considering the strength of the evidence demonstrating that both short and long sleep duration are associated with elevated mortality and elevated cardiometabolic disease risk, sleep is increasingly recognized as a major public health problem. In 2006, the Institute of Medicine released a report entitled, "Sleep disorders and sleep deprivation: an unmet public health problem". ${ }^{55}$ This report suggested that sleep loss, experienced in and outside of the context of sleep disorders, plays a major role in many public health issues, and that these relationships need to be better understood and addressed. The Institute of Medicine issued a subsequent report in 2010 on "resident duty hours," which focused on the public health implications of the many medical residents who are working hours that predispose them to health and safety risks. ${ }^{56}$ This report led to major changes in rules regarding medical residencies. ${ }^{57-65}$ Other safety critical industries have also begun to recognize the importance of sleep. For example, new or proposed regulations for commercial drivers, air traffic controllers, pilots, and rail workers aim to mitigate health and safety concerns associated with insufficient sleep. Finally, in 2010, adequate sleep has been included, for the first time, in the US federal program that delineates national health priorities and targets: Healthy People. ${ }^{66}$

In summary, insufficient and/or sleep duration has been repeatedly shown to increase mortality risk, and that this increased mortality is accompanied by (and perhaps partially explained by) increased CVD risk. These documented associations have led to the beginnings of public health campaigns addressing sleep related issues. The next step in addressing some of these associations is to identify and to assess potential mechanistic pathways by which sleep duration confers risk. One such pathway may be through elevations in proinflammatory responses associated with sleep duration.

\section{Proinflammatory biomarkers and CVD risk Inflammation and CVD}

Inflammation is well established as a key mechanism in the development of CVD. ${ }^{67}$ Inflammatory reactions are adaptive when they occur in response to an acute injury or illness and coordinate cytokines, adhesion molecules, and chemokines to counter the threat. The body does not adjust well to the prolonged presence of difficult to destroy microorganisms or chemicals that repeatedly evoke an immune response, and that create a state of chronic inflammation. ${ }^{68}$ Libby describes how the inflammatory process contributes to all stages of CVD, from the development of atherosclerotic plaques in the vascular wall to end stage thrombotic complications. ${ }^{69}$ This process begins with an increase in low density lipoprotein (LDL) molecules in the bloodstream due to poor diet, inactivity, and/or other factors. The LDL subsequently accumulates in the artery wall and activates the endothelial cells, which increases the expression of adhesion molecules. The endothelial cells produce chemokines which encourage monocytes, natural killer cells, and T-cells to migrate to the site and start producing proinflammatory cytokines. These cytokines (IL- $1 \beta$, TNF- $\alpha$, and interferon $\gamma$ ) stimulate leukocytes to produce IL- 6 which encourages the production of CRP. ${ }^{68}$ In addition to being clinically useful as a measure of systemic inflammation, IL-6 and CRP are independently associated with elevated CVD risk. ${ }^{70}$

\section{Sleep duration and inflammation}

Inflammation is a plausible mechanism linking sleep duration and CVD. There is evidence that sleep loss is associated with inflammation ${ }^{9,71-80}$ and negative cardiovascular outcomes. ${ }^{10,81,82}$ Recently, observational and experimental sleep deprivation studies have shown an association between sleep loss and proinflammatory processes that promote the development of atherosclerotic plaques. ${ }^{71,77}$ Other studies have also supported these findings, with associations between sleep duration and atherosclerosis risk markers. For example, results from the CARDIA (Coronary Artery Risk Development in Young Adults) cohort study have shown that short sleep duration is prospectively associated with coronary artery calcification among middle aged adults ${ }^{83}$ and other studies have shown that sleep duration is associated with carotid intima media thickness. ${ }^{84,85}$ For the purposes of this review, the following proinflammatory biomarkers have 
demonstrated (or suggested) associations with sleep duration: TNF- $\alpha$, IL-1, -6, and -17, CRP, coagulation molecules, cellular adhesion molecules, and visfatin.

\section{TNF- $\alpha$}

TNF (also referred to as tumor necrosis factor- $\alpha$ or TNF$\alpha$ ) is a cytokine produced by activated macrophages that stimulates acute phase reactions and is involved with systematic inflammation. TNF- $\alpha$ was aptly named when it was discovered to induce tumor cell apoptosis, ${ }^{86}$ or programmed cell death. In general, TNF- $\alpha$ promotes several cell functions related to immune cell proliferation and adhesion, and apoptosis. ${ }^{87}$ The primary functions of TNF- $\alpha$ include activation of nuclear factor kappa $\mathrm{B}$ ([NFKB] a protein complex that controls DNA transcription and is involved in cellular responses to stressors) and mitogen-activated protein kinase pathways (involved in many cellular processes, including response to stressors and regulation of gene expression) to influence immune response and cell regulation. At the TNF receptor, apoptosis is promoted through multiple pathways via caspase 8 and caspase 3 proteins.

The impact of sleep duration on TNF- $\alpha$ is not entirely clear. In a study that evaluated the effects of 12 nights of sleep restriction to 6 hours, 24-hour TNF- $\alpha$ was elevated in men, but not in women. ${ }^{88}$ In another study, no changes in TNF- $\alpha$ p55 receptor expression (a key component for many functions of TNF- $\alpha$ ) were found after 10 days of sleep restriction. ${ }^{79}$ These findings are consistent with a study of total sleep deprivation, where one night of total sleep deprivation was associated with elevated TNF- $\alpha$ secretion but not levels of receptors ${ }^{89}$ and a study of one night of sleep restriction, which showed an increase in TNF- $\alpha$ messenger (m)RNA expression..$^{90}$ In a less extreme example, when sleep was restricted to two 2-hour naps, no elevations in TNF- $\alpha$ were seen. ${ }^{91}$ Part of the reason for some inconsistent findings may be individual differences in vulnerability to sleep loss and the different receptor types studied. ${ }^{78}$ Only one study has investigated TNF- $\alpha$ in a population setting. ${ }^{92}$ In the Cleveland Family Study, shorter polysomnographic sleep was associated with elevated TNF- $\alpha$, such that each hour of sleep was associated with an $8 \%$ change in TNF- $\alpha .^{92}$ Taken together, these studies suggest that there is likely a relationship between sleep and TNF- $\alpha$, and that sleep may play a regulatory role in TNF- $\alpha$ function.

\section{Interleukins}

\section{IL-I}

The interleukin-1 (IL-1) family represents 11 proinflammatory cytokines, of which IL- $1 \alpha$ and IL- $1 \beta$ are the best studied.
IL- $1 \alpha$ or IL- $1 \beta$ binds to a ligand-binding chain (IL-1RI), which is followed by recruitment of a coreceptor chain (accessory protein or IL-1RAcP). A signal is initiated with recruitment of an adaptor protein to the Toll-IL-1 receptor domain. Several kinases are phosphorylated, and $\mathrm{NF} \kappa \mathrm{B}$ translocates to the nucleus, triggering expression of several inflammatory genes. ${ }^{93}$ The IL-1 family is often studied as the prototypical cytokine pathway mediating inflammation. In addition, neutralization of IL- $1 \beta$ in particular has demonstrated therapeutic utility in the treatment of several chronic diseases that are characterized by systemic inflammation. ${ }^{94}$

IL-1 is thought to play a role in sleep propensity. Early study have shown that when subjects were kept awake, IL-1 was increased during the night relative to recovery sleep. ${ }^{95}$ A later study have shown increased IL-1 in sleep deprived rabbits and that inhibition of IL- $1 \beta$ reduced sleep after sleep deprivation. ${ }^{96}$ Also, IL-1 peaks in the mid-afternoon, which coincides with increased sleepiness. ${ }^{95}$ Although IL-1 has not been studied relative to habitual sleep duration, in a study of five nights of sleep restriction to 4 hours, 13 healthy young men demonstrated elevated IL-1 $\beta$ at the mRNA level but not the protein level. ${ }^{97}$

\section{IL-6}

IL-6 is a proinflammatory cytokine secreted by T-cells and macrophages to stimulate the immune response. It is an important factor in the acute phase response and plays a number of important roles, including changing the body temperature setpoint and stimulating energy utilization in adipose tissue. IL- 6 has also been shown to be increased in obese individuals, ${ }^{98}$ specifically IL-6 release is $2-3$ times greater in visceral fat than in subcutaneous fat $(15 \%-30 \%$ comes from fat tissue). ${ }^{99}$ Although primarily proinflammatory, IL-6 is also involved in some anti-inflammatory processes, including the inhibition of TNF- $\alpha$ and IL-1, and stimulation of IL-10.

One reason that IL- 6 has been studied relative to sleep is that it is expressed according to a well characterized diurnal rhythm. Normally, IL-6 levels are highest at night, with elevations around sleep onset (although it is suppressed in slow wave sleep)..$^{95}$ The study in the laboratory have shown that sleep loss delays the nighttime peak of IL-6, and sleep deprivation alters IL- 6 rhythm across the day, including daytime oversecretion and nighttime undersecretion. ${ }^{95}$ Exogenous administration of IL-6 reduces slow wave sleep and rapid eye movement (REM) sleep at the beginning of the night, with a rebound later in the night. ${ }^{95}$ Despite sleep 
deprivation being associated with undersecretion at night, one study has found that IL-6 levels were elevated during night work. ${ }^{100}$

Several studies have explored the effects of partial sleep restriction on IL-6. In a study by Haack et al, IL-6 was elevated after 12 days of 4 hours of sleep, relative to 8 hours. ${ }^{79}$ These elevations were associated with increased pain ratings. ${ }^{79}$ In another study, after 12 nights of 6 hours of sleep opportunity, 24-hour IL-6 secretion was elevated, relative to 8 hours. ${ }^{88}$ In a more recent study, after five nights of sleep restriction to 4 hours, 13 healthy young men demonstrated elevated IL-6 at the mRNA level but not the protein level. ${ }^{97}$ Taken together, these findings suggest that sleep deprivation elevates IL-6 secretion over 24 hours.

Habitual sleep duration has also been examined relative to IL-6 levels. Longer sleep duration was associated with elevated IL-6 in the Cleveland Family Study, such that each hour of self-reported sleep (via questionnaire) was associated with a $7 \%$ increase in IL-6. ${ }^{92}$ This was replicated in a Taiwanese cohort, which found that long sleep duration ( $>8$ hours), assessed with a survey item, was associated with elevated IL-6 levels; ${ }^{101}$ however, other studies have found relationships in the other direction. In a study of elderly Alzheimer caregivers and controls, objectively measured sleep duration (operationalized as percent of actigraphic epochs scored as sleep) negatively associated with IL-6. ${ }^{102}$ In a study of mothers, sleep duration (assessed using a survey item) of $<5$ hours at 1 year postpartum was associated with elevated IL- 6 at 3 years postpartum. ${ }^{103}$

\section{IL-I7}

IL-17 is a proinflammatory cytokine that mediates delayed type inflammatory reactions. It increases recruitment of monocytes and neutrophils to the site of inflammation via the increased expression of chemokines (similar to interferon $\gamma$ ). It is produced by T-helper cells and is induced by IL-23. Its primary functions seem to be related to the response to external pathogens. IL-17 works in collaboration with IL-1 and TNF- $\alpha .{ }^{104}$ To date, one study has examined sleep restriction in the context of IL-17. After five nights of sleep restricted to 4 hours, 13 healthy young men demonstrated elevated IL-17 at the mRNA level and at the protein level. ${ }^{97}$

\section{CRP}

CRP is the primary marker associated with the acute phase response in humans (the formation of plasma proteins in response to an inflammatory stimulus). CRP is synthesized in the liver, via a pathway that involves IL-6, TNF- $\alpha$, and IL-1. ${ }^{105}$
CRP is a stable marker, and does not have a discernible circadian rhythm. Further, inflammation is a critical factor in the development and maintenance of atherosclerotic plaques, ${ }^{67,69,106,107}$ and CRP has been shown to play a role in inflammatory processes at the vascular endothelium ${ }^{108,109}$ and opsonizes LDL for uptake by macrophages in the atherosclerotic plaque. ${ }^{110}$

Epidemiologic studies have demonstrated that CRP is an independent predictor of short-term and long-term myocardial infarction and stroke. ${ }^{11-113}$ In a prospective study of 28,263 apparently healthy postmenopausal women studied over a mean period of 3 years, Ridker et al ${ }^{111}$ assessed 12 inflammatory biomarkers in terms of risk for cardiovascular events (ie, death from $\mathrm{CHD}$, nonfatal myocardial infarction or stroke, coronary revascularization). Among the 12 biomarkers, CRP was the strongest predictor of increased risk. The importance of CRP as a risk marker for CVD has been further confirmed in other samples. ${ }^{114-123}$

Several studies have investigated whether partial sleep deprivation results in increased CRP levels. Meier-Ewert et $\mathrm{al}^{80}$ randomly assigned 10 healthy adult subjects to either a group that restricted their sleep to 4.2 hours or a control group that was allowed 8.2 hours of sleep for ten consecutive days. CRP levels were assessed at the start and end of the protocol. During the control condition, CRP levels did not change significantly $(-0.026 \mathrm{mg} / \mathrm{dL}$ change, $P=0.72)$. However, during the partial sleep deprivation condition, CRP levels increased significantly $(+0.214 \mathrm{mg} / \mathrm{dL}$ change, $P<0.05)$. A more recent study by van Leeuwen et $\mathrm{al}^{17}$ assessed 13 healthy young men who were restricted to 4 hours in bed for five nights, followed by two nights of recovery sleep. This study assessed CRP at baseline, after sleep restriction, and after recovery. Following sleep restriction, CRP was increased when compared to baseline $(145 \%$ of baseline, $P<0.05)$, and continued to increase during recovery $(231 \%$ of baseline, $P<0.05)$. These studies suggest that shortened sleep produces an acute increase in CRP that is not immediately ameliorated by recovery. However, it is unclear whether this response generalizes to nonlaboratory conditions.

Large epidemiologic cohorts have been leveraged to examine associations between sleep duration and CRP levels in general population samples. Within the Nurses' Health Study (which used survey items for sleep duration), an association between long sleep duration ( $\geq 9$ hours) and CRP concentrations was significant even after adjusting for a number of demographic, socioeconomic, and health risk factors. ${ }^{124}$ Findings with regards to long sleep duration were also observed among both men and women $(\mathrm{N}=614)$ in the 
Cleveland Family Study. ${ }^{92}$ Results indicated that for every additional hour in sleep duration (measured using a survey item), CRP levels increased by $8 \%(P=0.004)$ after adjusting for age, sex, race, body mass index (BMI), waist circumference, and severity of sleep apnea.

Sex differences were reported for sleep duration and CRP among 4600 adults in the Whitehall Study ( $P$ for interaction $<0.05) .{ }^{125}$ Miller et al ${ }^{125}$ reported a null association between short and long sleep duration (assessed using a survey item) and CRP among men in that cohort after adjusting for covariates. Among women, however, long sleep ( $\geq 9$ hours) was associated with a 35\% increase in CRP levels after adjusting for age, marital status, BMI, smoking, systolic blood pressure, and triglyceride levels. ${ }^{125}$ Evidence for a significant association between short sleep and CRP among women was also reported in fully adjusted models.

A significant relationship between short sleep duration (assessed using polysomnography) and CRP was also found for 340 African American women enrolled in the Study of Women's Health across the Nation (SWAN) Study, although after adjustment for covariates, the effect was only seen among the 125 African American women. ${ }^{76}$ Importantly, further analysis showed a significant interaction with race/ ethnicity, and post-hoc analyses clarified that this relationship only existed among African American women. However, not all studies have documented significant relationships. In the Wisconsin Sleep Cohort ( $\mathrm{N}=907)$, no association was seen between CRP and short or long sleep duration in adjusted models. ${ }^{126}$ In this case, investigators examined self-reported as well as polysomnography assessed sleep duration, and also evaluated quadratic terms in their analysis. This study also did not demonstrate sex stratified or race stratified results; however, these findings are based on a sample of predominantly White participants. Additionally, Suarez et al ${ }^{127}$ did not report a significant association between self-reported habitual sleep duration and CRP among men, but the small sample size $(\mathrm{N}=210)$ and younger age group (mean age of 28 years) may account for this.

A recent study utilizing the 2007-2008 NHANES (National Health and Nutrition Examination Survey) cohort had as its goal to discern relationships between sleep duration and CRP in the American population $(\mathrm{N}=5587)$, while addressing some of the sample size and generalization limitations of previous studies. ${ }^{128}$ To address issues of low variability of CRP in the population, a polynomial regression analysis examined whether there was a linear or a U-shaped trend, even in the absence of any significant elevations among sleep duration groups, relative to 7 hours. To address the issue of overly inclusive sleep duration categories (that may obscure effects at the extremes of sleep duration), sleep duration was assessed as $<5,5,6,7,8,9$, and $>9$ hours, with 7 hours as the reference group. To address sex differences, analyses were conducted with men and women both combined and separately. To address race/ethnicity differences, interaction terms and stratified analyses looked at patterns in different groups. Linear and squared terms were significant in all models in the complete sample, with notable differences by sex and ethnoracial group. Overall, in models adjusted for sociodemographics and BMI, different patterns were observed for non Hispanic White (elevated CRP for $<5$ hours and $>9$ hours), Black/African American (elevated CRP for $<5$ hours and 8 hours), Hispanic/Latino (elevated CRP for $>9$ hours), and Asian/Other (higher in 9 and $>9$ hours and lower in 5 hours and 6 hours) groups. Ethnoracial groups also demonstrated patterning by sex. For example, long sleep effects were more prominent among women.

\section{Coagulation molecules}

Thrombogenesis (formation of blood clots) is a critical process involved in the management of damaged blood vessels. Damaged vessel walls are covered by a clot comprised of platelets and fibrin, which stops the bleeding and initiates vessel repair. Dysregulation of this process can result in excess bleeding or clotting. The formation of fibrin is largely based on the production of thrombin, which converts fibrinogen to fibrin. Fibrinogen is secreted by liver hepatocytes and high levels of circulating fibrinogen have been associated with CVD risk ${ }^{129,130}$ and reflect increased inflammation. In one study, long sleep duration ( $>8$ hours) was associated with elevated fibrinogen in a Taiwanese cohort. ${ }^{101}$ This was recently replicated in a study using data from 3942 women enrolled in the Women's Health Initiative, which found that long sleep duration ( $\geq 9$ hours), measured with a survey item, was associated with elevated fibrinogen among postmenopausal women. ${ }^{131}$ In addition, fibrinogen mediated the association between long sleep duration and CHD, as well as between long sleep duration and mortality, with supporting evidence of partial mediation of $6 \%-7 \%$. Thus, fibrinogen levels accounted for approximately $6 \%-7 \%$ of the relationship between long sleep duration and mortality.

When fibrin is degraded, one of the products is d-dimer, a biomarker for the formation of thrombotic disorders. Although d-dimer levels are usually very low, elevations have also been seen in conditions such as liver disease, pregnancy, and postsurgery. One study of 97 Alzheimer caregivers and 48 controls found that shorter actigraphic sleep duration 
was associated with elevated d-dimer levels. ${ }^{102}$ In this same study, d-dimer was negatively associated with sleep quality measured with the Pittsburgh Sleep Quality Index. ${ }^{102}$

\section{Adhesion molecules}

Another class of molecules that is upregulated as part of the inflammatory response is the adhesion molecules. Circulating leukocytes adhere poorly to the normal endothelium. ${ }^{132}$ Cholesterol accumulation in the artery wall leads to endothelial dysfunction as well as smooth muscle cell proliferation. ${ }^{67} \mathrm{~A}$ cascading inflammatory process leads to further accumulation of inflammatory cells, degradation of the extracellular matrix, and unstable lesions. ${ }^{67,133}$ This causes endothelial cells to be activated and express adhesion molecules. ${ }^{132}$ Intercellular adhesion molecule-1 (ICAM-1) is part of the largest family of endothelial adhesion molecules, is upregulated during inflammation after exposure to cytokines, and plays an important role in facilitating the movement of leukocytes to the inflamed area. ICAM-1 is also strongly upregulated by TNF- $\alpha$. One study found that both short sleep duration ( $<6$ hours) and long sleep duration ( $>8$ hours), based on a questionnaire item, was associated with elevated ICAM-1 in a Taiwanese cohort of 1020 adults aged 53 years and over. ${ }^{101}$ However, this study was limited by a cross-sectional measurement of ICAM-1; thus, no causal relationship between increased ICAM-1 and sleep duration can be concluded.

\section{Visfatin}

Visfatin, also known as nicotinamide phosphoribosyltransferase or pre- $\beta$ cell colony-enhancing factor, is an adipokine that serves a number of functions, including inhibition of neutrophil apoptosis and activation of insulin receptors (increasing insulin sensitivity). ${ }^{134}$ It induces expression of TNF- $\alpha$, IL- $1 \beta$, and induces IL- 6 activation in monocytes. ${ }^{135}$ It is highly expressed in visceral fat and correlates with obesity. ${ }^{136,137}$ Shorter sleep duration (assessed with polysomnography) was associated with elevated visfatin in a study of 493 subjects in the Cleveland Family Study, such that visfatin levels increased $14 \%$ for every hour decrease in sleep duration. ${ }^{138}$ This was likely driven by a relationship with REM sleep, since 1 hour less REM sleep was associated with a $31 \%$ increase in visfatin levels. ${ }^{138}$

\section{Limitations of existing studies}

In the literature reviewed, it was often the case that findings were conflicting. Many of the studies reporting significant associations evaluated several immune markers and, in many cases, positive findings were found for only some of the markers studied. It must be recognized that several predominantly negative studies, finding no association between sleep and immune markers, have also been published. For example, one study found no elevations among patients with kidney disease. ${ }^{139}$ Another study by Taheri et al found no association between sleep and CRP, ${ }^{126}$ a negative finding that was also demonstrated by Haack et al. ${ }^{79}$ Tuomilehto et al also found no association between sleep and both CRP and IL-6 in the context of a lifestyle intervention (which may have overshadowed any association). ${ }^{140}$ It is possible that the positive studies represent Type 1 error, and the true findings are negative. If a true relationship exists, however, then there are several reasons for the observed Type 2 error (lack of findings in the context of a true association). These include inconsistent and problematic definitions of sleep duration groups and heterogeneous sleep duration groups (mentioned above), as well as insufficient sample size, insufficient stratification, floor effects, and other factors.

\section{Insufficient sample size}

Most experimental studies of sleep deprivation or sleep restriction include small sample sizes which limit the generalization of these studies. Also, the interventional nature of these studies maximizes their ability to detect differences in a highly controlled environment, using highly precise measures. In observational studies, however, with no intervention, much larger sample sizes are required to observe small differences. Compared to sample sizes in the range of $10,{ }^{80} 13,{ }^{97} 18,{ }^{79}$ and $25,{ }^{88}$ population studies have generally included a larger number of participants. For example, proinflammatory markers relative to sleep duration have been assessed in the SWAN study $(\mathrm{N}=340),{ }^{76}$ the Cleveland Family Study $(\mathrm{N}=614),{ }^{92}$ the Wisconsin Sleep Cohort $(\mathrm{N}=907),{ }^{126}$ the Nurses' Health Study $(\mathrm{N}=935),{ }^{122}$ and the Taiwanese Social Environment and Biomarkers of Aging Study $(\mathrm{N}=1020) .{ }^{101}$ These studies, and most other population based studies, have needed hundreds of participants to demonstrate associations. But the most robust associations have been demonstrated in even larger populations, although there are only two studies that have included thousands of individuals. ${ }^{128,131}$ The recent study by Hale et al demonstrating that fibrinogen is associated with long sleep duration included 3942 participants from the Women's Health Initiative $^{131}$ and the study (described above) of CRP using NHANES investigated 5587 adults. ${ }^{128}$ These two studies were able to leverage their large sample size to address these 
issues in a more thorough way. This allowed, for example, sufficient numbers at the extremes of habitual sleep duration to be able to detect significant differences relative to much more normative sleep durations. Other studies (even those with hundreds of participants) have lacked the numbers at the very high and very low sleep durations. For example, elevated CRP was found for $<5$ and $>9$ hours of sleep in NHANES; ${ }^{131}$ most of the other studies could not even explore these subgroups, combining them with other sleep duration groups, and potentially obscuring effects.

\section{Floor effects for many biomarkers}

Circulating levels of proinflammatory biomarkers demonstrate significant floor effects in the general population, requiring large sample sizes to explore variability and to maximize statistical power. Transformations may be employed to address the skew and to allow the data to meet the key assumptions of the statistical model (ie, normal/ Gaussian distribution of predictor variables in a regression model), but these do not generally affect issues caused by reduced variability. Studies have detected a range of levels of biomarkers in relatively large sample sizes, ${ }^{112}$ although these samples are often selected for being at higher than normal risk of CVD or tend to be in aging populations. For example, categorizing respondents as having had a recent cardiac event yields tertiles of CRP levels reflecting protected, normal, and elevated risk of cardiometabolic disease that are not representative of a general population with a lower rate of morbidity or predisease states. ${ }^{141}$ Similarly tertiled values from a sample of the general population may be lower and may not yield such useful categories for subsequent cardiovascular event prediction.

\section{Insufficient stratification}

CRP levels and relationships between CRP and health outcomes are known to vary by sex, race, and ethnicity. ${ }^{142,143}$ Despite this, very few studies of sleep duration and inflammation have been adequately powered to explore interactions with these demographic factors. It has been reported that non Hispanic African American women and Hispanic/Latino women have elevated CRP levels when compared to other race groups. ${ }^{144}$ One study among women (mentioned above) suggested differences in patterns between sleep duration and inflammatory and coagulation markers by race. ${ }^{76}$ Previous findings from 1999-2000 NHANES suggested greater CRP levels among African American men and women, as well as Hispanic/Latino women when compared to Caucasian controls. ${ }^{143}$ Black/African American men and women have greater rates of CVD mortality when compared to other race groups and improvements in prevention strategies are essential. ${ }^{145,146}$ A previous report of sleep duration and CVD mortality among Asian populations have indicated that long sleep ( $>9$ hours) with high levels of sleep disturbance predicts the greatest risk of CVD. ${ }^{147}$ One study of sleep duration and CRP in Taiwanese adults has suggested that inflammation was significantly associated with long ( $>8$ hours), but not short ( $<6$ hours) sleep duration. ${ }^{101}$ These associations were significant when using a high CRP threshold ( $>10.0 \mathrm{mg} / \mathrm{dL})$, but not when using a lower CRP threshold ( $>3.0 \mathrm{mg} / \mathrm{dL})$ after adjustment for age, sex, waist circumference, reported health decline, diabetes, arthritis, heart disease, and depression.

Differences in the inflammatory reaction to sleep loss have also been evidenced. Men and women show marked differences in TNF- $\alpha$ changes associated with sleep deprivation. ${ }^{88}$ Also, men and women show different patterns of IL-6 and TNF- $\alpha$ secretion following sleep loss. ${ }^{75}$ Sleep restriction resulted in decreased adiponectin (an antiinflammatory hormone) among White but not Black women, and not at all among men. ${ }^{148}$ These findings suggest that the relationship between inflammatory biomarkers and CVD and/or sleep likely differs based on sex and/or race/ethnicity. Few studies have explored this consideration, however.

\section{Other factors that may play important roles}

There are a number of variables that may play a role in the relationship between sleep and inflammation. It has been previously suggested that the role of sleep in health outcomes is at least partially driven by social and environmental factors. $^{46,149}$ This may apply to inflammation. Although there is little evidence to support this claim, social engagement partially mediates the relationship between poor sleep and elevated IL-6 and e-selectin. ${ }^{150}$ It also partially mediates the relationship between actigraphic sleep efficiency and IL-6 in men. ${ }^{150}$ Also, the relationship between sleep quality and IL-6 in older adults depends on variability of sleep patterns, substance use, and insomnia. ${ }^{151}$ Cognitive behavioral therapy for sleep disturbances was found to reduce CRP, IL-18, and oxidized LDL. ${ }^{152}$

The role of social and interpersonal factors has still not yet been explored in detail. Christakis and Fowler ${ }^{153}$ have used a social network model to chart the relationship between social factors and obesity. It is possible that such an approach can be taken with sleep. Also, Suarez et al have found that anger, aggression, and hostility were associated with elevated TNF- $\alpha .{ }^{154}$ These and other similar factors may be related to 
hyperarousal (and potentially insomnia), suggesting that other psychological pathways linking sleep and inflammation exist. Similarly, alcohol may serve a mechanistic role linking sleep and inflammation. Alcohol is well known to interfere with sleep, ${ }^{155}$ although low doses of alcohol may be helpful for sleep. ${ }^{156}$ A nonlinear relationship between alcohol intake and inflammation in the Health, Aging, and Body Composition Study. ${ }^{157}$ Nondrinkers and heavy drinkers ( $>8$ drinks/week) were at an increased likelihood of elevated IL-6 and CRP (but not TNF- $\alpha$ ).

Another issue that pertains to the definition of sleep duration groups is the limited knowledge regarding international norms regarding sleep duration. It is plausible that regional and cultural differences regarding what is "short" or "normal" sleep duration may also play a role in differential vulnerability. For example, studies from Asian cohorts tend to show more short sleep duration than Western cohorts. ${ }^{101,158}$

Genetics may also play a role. In contrast to recognized sleep disorders, the genetics of sleep duration are poorly understood. The interaction between sleep duration and genetics may explain some of the negative and conflicting findings regarding the association between sleep duration and cardiovascular morbidity. When performing candidate gene re-sequencing in DNA from human families, He et $\mathrm{al}^{159}$ found a DEC2 point mutation in two individuals with shorter lifelong daily sleep times (average 6.25 hours) when compared with the noncarriers (average 8.06 hours), demonstrating that DEC2 may play an important role in regulating daily sleep time. However, the authors were not able to replicate this association in a testable mammalian model. The only reported genome wide analysis of sleep used data from the 749 subjects included in the Framingham Study Family Plate Set. ${ }^{160}$ The authors found a $17 \%$ heritability estimate for sleep duration and suggested that the circadian clock genes (casein kinase 2A2, prokineticin 2, and CLOCK) modulated habitual bedtime and sleep duration. The one study to examine short sleep duration and hypertension suggested that specific genomic markers were associated with short sleep duration and increased hypertension risk, but only for premenopausal women. ${ }^{161}$ Although suggestive, no definitive conclusions regarding the genetics of sleep duration and CVD are possible until well defined larger scale replication studies confirm these initial findings.

The differential genetic susceptibility to complications from sleep loss must also be considered when discussing sleep duration, inflammation, and CVD. The physical effects of sleep loss can vary widely and depend, at least partially, on individual genetic factors. The heritability of performance deficit accumulation during 38 hours of sleep deprivation in a sample of 59 monozygotic and 41 dizygotic same sex twin pairs with a normal polysomnogram was 0.834 , indicating a highly heritable trait. ${ }^{162}$ Unfortunately, this same study was not able to find a genotype associated with increased susceptibility to the negative performance effects of sleep loss.

Finally, sleep duration may interact with sleep disturbance to exacerbate cardiometabolic risk. There have been a number of studies from Bixler, Vgontzas, Fernandez-Mendoza et $\mathrm{al}^{163-168}$ that have explored the interactive effects of short sleep duration and insomnia. Several studies from this group found that short sleep duration and insomnia together are associated with elevated hypothalamic-pituitary-adrenal axis activity consistent with an elevated chronic stress response. ${ }^{163,164}$ Further, this group has demonstrated that this combination confers elevated risk for hypertension, ${ }^{165}$ type 2 diabetes, ${ }^{166}$ cognitive dysfunction, ${ }^{167}$ and mortality. ${ }^{168}$

\section{Future research directions}

There are several important future research directions suggested by the findings reviewed above. First, the role of sleep as a public health issue needs to be addressed further. This may involve further integration of sleep measures into existing epidemiologic cohorts. It may also involve focusing research efforts on domains that could presumably drive policy changes regarding health care delivery, public education, and integration of sleep into other public health models.

Second, the mechanistic pathways linking sleep patterns, as they are experienced in the general population, need to be further explicated. Mechanisms have been proposed for the relationship between mortality and both short sleep ${ }^{46}$ and long sleep ${ }^{3}$ durations but these relationships have not been thoroughly tested. Currently, there are hundreds of papers that have demonstrated that sleep duration is associated with cardiometabolic risk. Although fewer papers have explicitly addressed inflammation, the preponderance of these papers lack either generalization to the population (by studying small or homogeneous samples) or precision in sleep measures (by employing sleep measures that are not validated and/or do not capture habitual sleep). Observational studies need to employ standard sleep measures and account for both sleep duration and quality, as well as measures of inflammation. Experimental studies need to employ samples diverse enough to generalize to the population at large. Until the epidemiologic and laboratory approaches can be reconciled, there will be a barrier to understanding any potential causal relationships. ${ }^{1}$ 
Third, there is a need for further studies exploring genetic variants and their impact on inflammatory markers in vivo as they relate to sleep duration and CVD risk. In recent studies, single nucleotide polymorphisms in the NOX (nicotinamide adenine dinucleotide phosphate-oxidase) p22phox gene have been found to be associated with reduced NOX activity levels (markers of oxidative stress and neuroinflammation) in children with obstructive sleep apnea (OSA). ${ }^{169}$ Increased production of TNF- $\alpha$ (marker of inflammation) both in vitro and in vivo has been associated with a functional variant in the TNF- $\alpha$ gene, consisting of a guanine to adenine substitution at position -308 in children with OSA. ${ }^{170}$ As inflammation is recognized as playing a role in all stages of the atherosclerotic disease process, evaluation of genetic variants and inflammation will aid in identifying patients at high risk for future cardiovascular events. Future studies should incorporate both genetic and biological markers to clarify the mechanisms behind sleep duration and CVD risk.

Fourth, further understanding is needed regarding how the relationship between sleep duration and inflammation depends on sex and race/ethnicity, and how these relationships may be dynamic across the life span. Studies that have begun to explore this complicated relationship have generally confirmed that a simple, one size fits all model is not appropriate to this question. A more nuanced approach is needed. For example, the relationship between the cardioprotective effects of sleep and inflammation may be different among premenopausal and postmenopausal women. Also, the effects of race/ethnicity on sleep are likely complex and may be related to factors such as socioeconomics, ${ }^{149}$ country of origin, ${ }^{171}$ cultural issues, ${ }^{172-174}$ beliefs, and attitudes about sleep. ${ }^{175}$

\section{Conclusion}

Obtaining sleep of sufficient quantity and quality is an important public health issue. Habitual sleep duration is associated with morbidity (for cardiometabolic disease in particular) and mortality. Understanding the potential mechanistic pathways will help to develop interventions that may mitigate the adverse effects of suboptimal sleep obtained by segments of the general population. An association between both short and long sleep duration and a proinflammatory state has been described in the literature, and several inflammatory pathways are implicated. In particular, the following molecules have been studied: TNF- $\alpha$, IL-1, -6, and -17, CRP, coagulation molecules, cellular adhesion molecules, and visfatin. The existing literature is limited, however, by many inconsistencies. These findings seen in the literature may be due to a generally weak association and/or are complicated by problems arising at the level of sampling and measurement. Future studies are needed to better understand this relationship.

\section{Acknowledgments}

This work was supported by the National Heart, Lung, and Blood Institute (K23HL110216), the National Institute of Environmental Health Sciences (R21ES022931), and the University of Pennsylvania CTSA (Clinical and Translational Science Award) (UL1RR024134). Gratitude for input and guidance in the development of this manuscript is extended to Allan Pack MBChB PhD, Karen Teff PhD, and Steven Siegel MD PhD.

\section{Disclosure}

The authors report no conflict of interest in this work.

\section{References}

1. Grandner MA, Patel NP, Gehrman PR, Perlis ML, Pack AI. Problems associated with short sleep: bridging the gap between laboratory and epidemiological studies. Sleep Med Rev. 2010;14:239-247.

2. Knutson KL. Sleep duration and cardiometabolic risk: a review of the epidemiologic evidence. Best Pract Res Clin Endocrinol Metab. 2010;24(5):731-743.

3. Grandner MA, Drummond SP. Who are the long sleepers? Towards an understanding of the mortality relationship. Sleep Med Rev. 2007;11(5): 341-360.

4. Youngstedt SD, Kripke DF. Long sleep and mortality: rationale for sleep restriction. Sleep Med Rev. 2004;8(3):159-174.

5. Lange T, Born J. The immune recovery function of sleep - tracked by neutrophil counts. Brain Behav Immun. 2011;25(1):14-15.

6. Gorczynski L, Terzioglu E, Waelli T, Gorczynski Rm. Aging, sleep, and immunity. In: Pandi-Perumal SR, Cardinali DP, Chrousos GP, editors. Neuroimmunology of Sleep. New York, NY: Springer; 2007: 133-153.

7. Majde JA, Krueger JM. Links between the innate immune system and sleep. J Allergy Clin Immunol. 2005;116(6):1188-1198.

8. Krueger JM, Majde JA, Rector DM. Cytokines in immune function and sleep regulation. In: Montagna P, Chokroverty S, editors. Sleep Disorders. Edinburgh: Elsevier; 2011:229-240.

9. Aldabal L, Bahammam AS. Metabolic, endocrine, and immune consequences of sleep deprivation. Open Respir Med J. 2011;5:31-43.

10. Faraut B, Boudjeltia KZ, Vanhamme L, Kerkhofs M. Immune, inflammatory and cardiovascular consequences of sleep restriction and recovery. Sleep Med Rev. 2012;16(2):137-149.

11. Hammond EC. Some preliminary findings on physical complaints from a prospective study of 1,064,004 men and women. Am J Public Health Nations Health. 1964;54:11-23.

12. Kripke DF, Simons RN, Garfinkel L, Hammond EC. Short and long sleep and sleeping pills. Is increased mortality associated? Arch Gen Psychiatry. 1979;36(1):103-116.

13. Wingard DL, Berkman LF. Mortality risk associated with sleeping patterns among adults. Sleep. 1983;6(2):102-107.

14. Wingard DL, Berkman LF, Brand RJ. A multivariate analysis of health-related practices: a nine-year mortality follow-up of the Alameda County Study. Am J Epidemiol. 1982;116(5):765-775.

15. Breslow L, Enstrom JE. Persistence of health habits and their relationship to mortality. Preventice Medicine. 1980;9:469-483.

16. Kaplan GA, Seeman TE, Cohen RD, Knudsen LP, Guralnik J. Mortality among the elderly in the Alameda County Study: behavioral and demographic risk factors. Am J Public Health. 1987;77(3):307-312. 
17. Belloc NB. Relationship of health practices and mortality. Prev Med. 1973;2(1):67-81.

18. Branch LG, Jette AM. Personal health practices and mortality among the elderly. Am J Public Health. 1984;74(10):1126-1129.

19. Rumble R, Morgan K. Hypnotics, sleep, and mortality in elderly people. J Am Geriatr Soc. 1992;40(8):787-791.

20. Gale C, Martyn C. Larks and owls and health, wealth, and wisdom. BMJ. 1998;317(7174):1675-1677.

21. Pollak CP, Perlick D, Linsner JP, Wenston J, Hsieh F. Sleep problems in the community elderly as predictors of death and nursing home placement. J Community Health. 1990;15(2):123-135.

22. Ruigomez A, Alonso J, Anto JM. Relationship of health behaviours to five-year mortality in an elderly cohort. Age Ageing. 1995;24(2):113-119.

23. Tsubono Y, Fukao A, Hisamichi S. Health practices and mortality in a rural Japanese population. Tohoku J Exp Med. 1993;171(4):339-348.

24. Kojima M, Wakai K, Kawamura T, et al. Sleep patterns and total mortality: a 12-year follow-up study in Japan. J Epidemiol. 2000; 10(2):87-93.

25. Goto A, Yasumura S, Nishise Y, Sakihara S. Association of health behavior and social role with total mortality among Japanese elders in Okinawa, Japan. Aging Clin Exp Res. 2003;15(6):443-450.

26. Amagai Y, Ishikawa S, Gotoh T, et al. Sleep duration and mortality in Japan: the Jichi Medical School Cohort Study. J Epidemiol. 2004;14(4): 124-128.

27. Tamakoshi A, Ohno Y. Self-reported sleep duration as a predictor of allcause mortality: results from the JACC study, Japan. Sleep. 2004;27(1): 51-54.

28. Lan TY, Lan TH, Wen CP, Lin YH, Chuang YL. Nighttime sleep, Chinese afternoon nap, and mortality in the elderly. Sleep. 2007;30(9): 1105-1110.

29. Shankar A, Koh WP, Yuan JM, Lee HP, Yu MC. Sleep duration and coronary heart disease mortality among Chinese adults in Singapore: a populationbased cohort study. Am J Epidemiol. 2008;168(12): 1367-1373.

30. Burazeri G, Gofin J, Kark JD. Over 8 hours of sleep - marker of increased mortality in Mediterranean population: follow-up population study. Croat Med J. 2003;44(2):193-198.

31. Mallon L, Broman JE, Hetta J. Sleep complaints predict coronary artery disease mortality in males: a 12-year follow-up study of a middle-aged Swedish population. J Intern Med. 2002;251(3):207-216.

32. Hublin C, Partinen M, Koskenvuo M, Kaprio J. Sleep and mortality: a population-based 22-year follow-up study. Sleep. 2007;30(10): 1245-1253.

33. Castro-Costa E, Dewey ME, Ferri CP, et al. Association between sleep duration and all-cause mortality in old age: 9-year follow-up of the Bambui Cohort Study, Brazil. J Sleep Res. 2011;20(2):303-310.

34. Huppert FA, Whittington JE. Symptoms of psychological distress predict 7-year mortality. Psychol Med. 1995;25(5):1073-1086.

35. Heslop P, Smith GD, Metcalfe C, Macleod J, Hart C. Sleep duration and mortality: The effect of short or long sleep duration on cardiovascular and all-cause mortality in working men and women. Sleep Med. 2002;3(4):305-314.

36. Ferrie JE, Shipley MJ, Cappuccio FP, et al. A prospective study of change in sleep duration: associations with mortality in the Whitehall II cohort. Sleep. 2007;30(12):1659-1666.

37. Qureshi AI, Giles WH, Croft JB, Bliwise DL. Habitual sleep patterns and risk for stroke and coronary heart disease: a 10-year follow-up from NHANES I. Neurology. 1997;48(4):904-911.

38. Gottlieb DJ, Schulman DA, Nam BH, D'Agostino RA, Kannel WA. Sleep duration predicts mortality: the Framingham Study. Sleep. 2002;25(Suppl):A108

39. Kripke DF, Garfinkel L, Wingard DL, Klauber MR, Marler MR. Mortality associated with sleep duration and insomnia. Arch Gen Psychiatry. 2002;59(2):131-136.

40. Ayas NT, White DP, Manson JE, et al. A prospective study of sleep duration and coronary heart disease in women. Arch Intern Med. 2003;163(2):205-209.
41. Dew MA, Hoch CC, Buysse DJ, et al. Healthy older adults' sleep predicts all-cause mortality at 4 to 19 years of follow-up. Psychosom Med. 2003;65(1):63-73.

42. Patel SR, Ayas NT, Malhotra MR, et al. A prospective study of sleep duration and mortality risk in women. Sleep. 2004;27(3):440-444.

43. Gangwisch JE, Heymsfield SB, Boden-Albala B, et al. Sleep duration as a risk factor for diabetes incidence in a large US. sample. Sleep. 2008;30(12):1667-1673.

44. Gallicchio L, Kalesan B. Sleep duration and mortality: a systematic review and meta-analysis. J Sleep Res. 2009;18(2):148-158.

45. Cappuccio FP, D'Elia L, Strazzullo P, Miller MA. Sleep duration and all-cause mortality: a systematic review and meta-analysis of prospective studies. Sleep. 2010;33(5):585-592.

46. Grandner MA, Patel NP, Hale L, Moore M. Mortality associated with sleep duration: The evidence, the possible mechanisms, and the future. Sleep Med Rev. 2010;14:191-203.

47. Grandner MA, Patel NP. From sleep duration to mortality: implications of meta-analysis and future directions. J Sleep Res. 2009;18(2): 145-147.

48. Bliwise DL, Young TB. The parable of parabola: what the U-shaped curve can and cannot tell us about sleep. Sleep. 2007;30(12):1614-1615.

49. Heron M. Deaths: Leading causes for 2009. National Vital Statistics Reports. 2012;61(7):1-95.

50. Mokdad AH, Marks JS, Stroup DF, Gerberding JL. Actual causes of death in the United States, 2000. JAMA. 2004;291(10):1238-1245.

51. Hoevenaar-Blom MP, Spijkerman AM, Kromhout D, van den Berg JF, Verschuren WM. Sleep duration and sleep quality in relation to 12-year cardiovascular disease incidence: the MORGEN study. Sleep. 2011; 34(11):1487-1492.

52. Bansil P, Kuklina EV, Merritt RK, Yoon PW. Associations between sleep disorders, sleep duration, quality of sleep, and hypertension: results from the National Health and Nutrition Examination Survey, 2005 to 2008. J Clin Hypertens (Greenwich). 2011;13(10):739-743.

53. Sabanayagam C, Shankar A. Sleep duration and cardiovascular disease: results from the National Health Interview Survey. Sleep. 2010;33(8):1037-1042.

54. Cappuccio FP, Cooper D, D’Elia L, Strazzullo P, Miller MA. Sleep duration predicts cardiovascular outcomes: a systematic review and metaanalysis of prospective studies. Eur Heart J. 2011;32(12):1484-1492.

55. Institute of Medicine (US) Committee on Sleep Medicine and Research. Sleep Disorders and Sleep Deprivation: An Unmet Public Health Problem. Colten HR, Altevogt BM, editors. Washington (DC): National Academies Press; 2006.

56. Committee on Optimizing Graduate Medical Trainee (Resident) Hours and Work Schedules to Improve Patient Safety. Resident Duty Hours: Enhancing Sleep, Supervision, and Safety. Ulmer C, Wolman DM, Johns MME, editors. Washington (DC): National Academies Press; 2009.

57. Zohar D, Tzischinsky O, Epstein R, Lavie P. The effects of sleep loss on medical residents' emotional reactions to work events: a cognitiveenergy model. Sleep. 2005;28(1):47-54.

58. Weinger MB, Ancoli-Israel S. Sleep deprivation and clinical performance. JAMA. 2002;287(8):955-957.

59. Borman KR, Biester TW, Jones AT, Shea JA. Sleep, supervision, education, and service: views of junior and senior residents. J Surg Educ. 2011;68(6):495-501.

60. Borman KR, Fuhrman GM; Association Program Directors in Surgery. "Resident Duty Hours: Enhancing Sleep, Supervision, and Safety": response of the Association of Program Directors in Surgery to the December 2008 Report of the Institute of Medicine. Surgery. 2009; 146(3):420-427.

61. Britt LD, Sachdeva AK, Healy GB, Whalen TV, Blair PG; Members of ACS task Force on Resident Duty Hours. Resident duty hours in surgery for ensuring patient safety, providing optimum resident education and training, and promoting resident well-being: a response from the American College of Surgeons to the Report of the Institute of Medicine, "Resident Duty Hours: Enhancing Sleep, Supervision, and Safety”. Surgery. 2009;146(3):398-409. 
62. Lewis FR. Comment of the American Board of Surgery on the recommendations of the Institute of Medicine Report, "Resident Duty Hours: Enhancing Sleep, Supervision, and Safety”. Surgery. 2009;146(3): 410-419.

63. Sataloff RT. Resident duty hours: concerns and consequences. Ear Nose Throat J. 2009;88(3):812-816.

64. Blatman KH. The Institute of Medicine resident work hours recommendations: a resident's viewpoint. J Clin Sleep Med. 2009; $5(1): 13$.

65. Meinke L. The Institute of Medicine resident work hours recommendations: a program director's viewpoint. J Clin Sleep Med. 2009;5(1):12.

66. Office of Disease Prevention and Health Promotion. Healthy People 2020 Objective Topic Areas. Washington, DC: US Department of Health and Human Services; 2011.

67. Ross R. Atherosclerosis - an inflammatory disease. $N$ Engl J Med. 1999;340(2):115-126.

68. Motivala SJ. Sleep and inflammation: psychoneuroimmunology in the context of cardiovascular disease. Ann Behav Med. 2011;42(2):141-152.

69. Libby P. Inflammation and cardiovascular disease mechanisms. Am J Clin Nutr. 2006;83(2):456S-460S.

70. Solarz DE, Mullington JM, Meier-Ewert HK. Sleep, inflammation and cardiovascular disease. Front Biosci (Elite Ed). 2012;4:2490-2501.

71. Besedovsky L, Lange T, Born J. Sleep and immune function. Pflugers Arch. 2012;463(1):121-137.

72. Illi J, Miaskowski C, Cooper B, et al. Association between pro- and antiinflammatory cytokine genes and a symptom cluster of pain, fatigue, sleep disturbance, and depression. Cytokine. 2012;58(3):437-447.

73. Zielinski MR, Mark Davis J, Fadel JR, Youngstedt SD. Influence of chronic moderate sleep restriction and exercise on inflammation and carcinogenesis in mice. Brain Behav Immun. 2012;26(4):672-679.

74. Wisor JP, Schmidt MA, Clegern WC. Evidence for neuroinflammatory and microglial changes in the cerebral response to sleep loss. Sleep. 2011;34(3):261-272.

75. Irwin MR, Carrillo C, Olmstead R. Sleep loss activates cellular markers of inflammation: sex differences. Brain Behav Immun. 2010;24(1): 54-57.

76. Matthews KA, Zheng H, Kravitz HM, et al. Are inflammatory and coagulation biomarkers related to sleep characteristics in mid-life women?: Study of Women's Health across the Nation sleep study. Sleep. 2010;33(12):1649-1655.

77. Mullington JM, Simpson NS, Meier-Ewert HK, Haack M. Sleep loss and inflammation. Best Pract Res Clin Endocrinol Metab. 2010;24(5):775-784.

78. Mullington JM, Haack M, Toth M, Serrador JM, Meier-Ewert HK Cardiovascular, inflammatory, and metabolic consequences of sleep deprivation. Prog Cardiovasc Dis. 2009;51(4):294-302.

79. Haack M, Sanchez E, Mullington JM. Elevated inflammatory markers in response to prolonged sleep restriction are associated with increased pain experience in healthy volunteers. Sleep. 2007;30(9):1145-1152.

80. Meier-Ewert HK, Ridker PM, Rifai N, et al. Effect of sleep loss on C-reactive protein, an inflammatory marker of cardiovascular risk. J Am Coll Cardiol. 2004;43(4):678-683.

81. Miller MA. Association of inflammatory markers with cardiovascular risk and sleepiness. J Clin Sleep Med. 2011;7(Supp1 5):S31-S33.

82. Lam JC, Ip MS. Sleep and the metabolic syndrome. Indian J Med Res. 2010;131:206-216.

83. King CR, Knutson KL, Rathouz PJ, Sidney S, Liu K, Lauderdale DS. Short sleep duration and incident coronary artery calcification. JAMA 2008;300(24):2859-2866

84. Sands MR, Lauderdale DS, Liu K, et al. Short sleep duration is associated with carotid intima-media thickness among men in the Coronary Artery Risk Development in Young Adults (CARDIA) Study. Stroke. 2012;43(11):2858-2864.

85. Abe, T., T. Aoki, S. Yata and M. Okada (2011). Sleep duration is significantly associated with carotid artery atherosclerosis incidence in a Japanese population. Atherosclerosis 217(2): 509-513.
86. Pfeffer K. Biological functions of tumor necrosis factor cytokines and their receptors. Cytokine Growth Factor Rev. 2003;14(3-4):185-191.

87. Jain S, Mills PJ. Cytokines, chronic stress, and fatigue. In: Fink G, editor. Encyclopedia of Stress, 2nd ed. Oxford: Academic Press; 2007:698-704.

88. Vgontzas AN, Zoumakis E, Bixler EO, et al. Adverse effects of modest sleep restriction on sleepiness, performance, and inflammatory cytokines. J Clin Endocrinol Metab. 2004;89(5):2119-2126.

89. Chennaoui M, Sauvet F, Drogou C, et al. Effect of one night of sleep loss on changes in tumor necrosis factor alpha (TNF-alpha) levels in healthy men. Cytokine. 2011;56(2):318-324.

90. Irwin MR, Wang M, Campomayor CO, Collado-Hidalgo A, Cole S Sleep deprivation and activation of morning levels of cellular and genomic markers of inflammation. Arch Intern Med. 2006;166(16): 1756-1762.

91. Shearer WT, Reuben JM, Mullington JM, et al. Soluble TNF-alpha receptor 1 and IL-6 plasma levels in humans subjected to the sleep deprivation model of spaceflight. JAllergy Clin Immunol. 2001;107(1): 165-170.

92. Patel SR, Zhu X, Storfer-Isser A, et al. Sleep duration and biomarkers of inflammation. Sleep. 2009;32(2):200-204.

93. Dinarello CA. A clinical perspective of IL-1 $\beta$ as the gatekeeper of inflammation. Eur J Immunol. 2011;41(5):1203-1217.

94. Dinarello CA, Simon A, van der Meer JW. Treating inflammation by blocking interleukin-1 in a broad spectrum of diseases. Nat Rev Drug Discov. 2012;11(8):633-652.

95. Kapsimalis F, Basta M, Varouchakis G, Gourgoulianis K, Vgontzas A Kryger M. Cytokines and pathological sleep. Sleep Med. 2008;9(6): 603-614.

96. Opp, M. R. and J. M. Krueger (1994). Anti-interleukin-1 beta reduces sleep and sleep rebound after sleep deprivation in rats. Am J Physiol 266(3 Pt 2): R688-695.

97. van Leeuwen WM, Lehto M, Karisola P, et al. Sleep restriction increases the risk of developing cardiovascular diseases by augmenting proinflammatory responses through IL-17 and CRP. PLoS ONE. 2009;4(2):e4589.

98. Bastard JP, Maachi M, Lagathu C, et al. Recent advances in the relationship between obesity, inflammation, and insulin resistance. Eur Cytokine Netw. 2006;17(1):4-12.

99. Fried SK, Bunkin DA, Greenberg AS. Omental and subcutaneous adipose tissues of obese subjects release interleukin-6: depot difference and regulation by glucocorticoid. J Clin Endocrinol Metab. 1998;83(3):847-850

100. Khosro S, Alireza S, Omid A, Forough S. Night work and inflammatory markers. Indian J Occup Environ Med. 2011;15(1):38-41.

101. Dowd JB, Goldman N, Weinstein M. Sleep duration, sleep quality, and biomarkers of inflammation in a Taiwanese population. Ann Epidemiol. 2011;21(11):799-806.

102. von Kanel R, Ancoli-Israel S, Dimsdale JE, et al. Sleep and biomarkers of atherosclerosis in elderly Alzheimer caregivers and controls. Gerontology. 2010;56(1):41-50.

103. Taveras EM, Rifas-Shiman SL, Rich-Edwards JW, Mantzoros CS. Maternal short sleep duration is associated with increased levels of inflammatory markers at 3 years postpartum. Metabolism. 2011;60(7): 982-986.

104. Chiricozzi A, Guttman-Yassky E, Suarez-Farinas M, et al. Integrative responses to IL-17 and TNF-alpha in human keratinocytes account for key inflammatory pathogenic circuits in psoriasis. J Invest Dermatol. 2011;131(3):677-687.

105. Castell JV, Gomez-Lechon MJ, David M, Fabra R, Trullenque R, Heinrich PC. Acute-phase response of human hepatocytes: regulation of acute-phase protein synthesis by interleukin-6. Hepatology. 1990; 12(5):1179-1186.

106. Ruberg FL, Loscalzo J. Inflammation and atherosclerosis. In: Loscalzo J, editor. Molecular Mechanisms of Atherosclerosis. Boca Raton, FL: Taylor and Francis; 2005:59-81. 
107. Libby P. Atherosclerosis: disease biology affecting the coronary vasculature. Am J Cardiol. 2006;98(12A):3Q-9Q.

108. Lagrand WK, Visser CA, Hermens WT, et al. C-reactive protein as a cardiovascular risk factor: more than an epiphenomenon? Circulation. 1999;100(1):96-102.

109. Pasceri V, Willerson JT, Yeh ET. Direct proinflammatory effect of C-reactive protein on human endothelial cells. Circulation. 2000; 102(18):2165-2168.

110. Zwaka TP, Hombach V, Torzewski J. C-reactive protein-mediated low density lipoprotein uptake by macrophages: implications for atherosclerosis. Circulation. 2001;103(9):1194-1197.

111. Ridker PM, Hennekens CH, Buring JE, Rifai N. C-reactive protein and other markers of inflammation in the prediction of cardiovascular disease in women. $N$ Engl J Med. 2000;342(12):836-843.

112. Ridker PM. High-sensitivity C-reactive protein: potential adjunct for global risk assessment in the primary prevention of cardiovascular disease. Circulation. 2001;103(13):1813-1818.

113. Libby P, Ridker PM, Hansson GK. Progress and challenges in translating the biology of atherosclerosis. Nature. 2011;473(7347):317-325.

114. Kuller LH, Tracy RP, Shaten J, Meilahn EN. Relation of C-reactive protein and coronary heart disease in the MRFIT nested case-control study. Multiple Risk Factor Intervention Trial. Am J Epidemiol. 1996; 144(6):537-547.

115. Ridker PM, Cushman M, Stampfer MJ, Tracy RP, Hennekens CH. Inflammation, aspirin, and the risk of cardiovascular disease in apparently healthy men. $N$ Engl J Med. 1997;336(14):973-979.

116. Ridker PM, Cushman M, Stampfer MJ, Tracy RP, Hennekens CH. Plasma concentration of C-reactive protein and risk of developing peripheral vascular disease. Circulation. 1998;97(5):425-428.

117. Tracy RP, Lemaitre RN, Psaty BM, et al. Relationship of C-reactive protein to risk of cardiovascular disease in the elderly. Results from the Cardiovascular Health Study and the Rural Health Promotion Project. Arterioscler Thromb Vasc Biol. 1997;17(6):1121-1127.

118. Ridker PM, Buring JE, Shih J, Matias M, Hennekens CH. Prospective study of C-reactive protein and the risk of future cardiovascular events among apparently healthy women. Circulation. 1998;98(8): 731-733.

119. Koenig W, Sund M, Frohlich M, et al. C-Reactive protein, a sensitive marker of inflammation, predicts future risk of coronary heart disease in initially healthy middle-aged men: results from the MONICA (Monitoring Trends and Determinants in Cardiovascular Disease) Augsburg Cohort Study, 1984 to 1992. Circulation. 1999;99(2):237-242.

120. Roivainen M, Viik-Kajander M, Palosuo T, et al. Infections, inflammation, and the risk of coronary heart disease. Circulation. 2000; 101(3):252-257.

121. Harris TB, Ferrucci L, Tracy RP, et al. Associations of elevated interleukin-6 and C-reactive protein levels with mortality in the elderly. Am J Med. 1999;106(5):506-512.

122. Danesh J, Whincup P, Walker M, et al. Low grade inflammation and coronary heart disease: prospective study and updated meta-analyses. BMJ. 2000;321(7255):199-204.

123. Mendall MA, Strachan DP, Butland BK, et al. C-reactive protein: relation to total mortality, cardiovascular mortality and cardiovascular risk factors in men. Eur Heart J. 2000;21(19):1584-1590.

124. Williams CJ, Hu FB, Patel SR, Mantzoros CS. Sleep duration and snoring in relation to biomarkers of cardiovascular disease risk among women with type 2 diabetes. Diabetes Care. 2007;30(5): $1233-1240$.

125. Miller MA, Kandala NB, Kivimaki M, et al. Gender differences in the cross-sectional relationships between sleep duration and markers of inflammation: Whitehall II study. Sleep. 2009;32(7):857-864.

126. Taheri S, Austin D, Lin L, Nieto FJ, Young T, Mignot E. Correlates of serum C-reactive protein (CRP) - no association with sleep duration or sleep disordered breathing. Sleep. 2007;30(8):991-996.

127. Suarez EC. Self-reported symptoms of sleep disturbance and inflammation, coagulation, insulin resistance and psychosocial distress: evidence for gender disparity. Brain Behav Immun. 2008;22(6):960-968.
128. Grandner MA, Buxton OM, Jackson N, Sands MR, Pandey AK, Jean-Louis G. Extreme sleep durations and increased C-reactive protein: effects of sex and ethnoracial group. Sleep. Published 2013;769-779.

129. Martinez-Vila E, Paramo JA, Beloqui O, et al. Independent association of fibrinogen with carotid intima-media thickness in asymptomatic subjects. Cerebrovasc Dis. 2003;16(4):356-362.

130. Temelkova-Kurktschiev T, Koehler C, Henkel E, Hanefeld M. Leukocyte count and fibrinogen are associated with carotid and femoral intima-media thickness in a risk population for diabetes. Cardiovasc Res. 2002;56(2):277-283.

131. Hale L, Parente V, Dowd JB, et al. Fibrinogen may mediate the association between long sleep duration and coronary heart disease. $J$ Sleep Res. Epub December 6, 2012.

132. Libby P. Inflammation in atherosclerosis. Nature. 2002;420(6917): 868-874.

133. Lerman A, Zeiher AM. Endothelial function: cardiac events. Circulation. 2005;111(3):363-368.

134. Xie H, Tang SY, Luo XH, et al. Insulin-like effects of visfatin on human osteoblasts. Calcif Tissue Int. 2007;80(3):201-210.

135. Moschen AR, Kaser A, Enrich B, et al. Visfatin, an adipocytokine with proinflammatory and immunomodulating properties. J Immunol. 2007;178(3):1748-1758

136. Chen MP, Chung FM, Chang DM, et al. Elevated plasma level of visfatin/pre-B cell colony-enhancing factor in patients with type 2 diabetes mellitus. J Clin Endocrinol Metab. 2006;91(1):295-299.

137. Sandeep S, Velmurugan K, Deepa R, Mohan V. Serum visfatin in relation to visceral fat, obesity, and type 2 diabetes mellitus in Asian Indians. Metabolism. 2007;56(4):565-570.

138. Hayes AL, Xu F, Babineau D, Patel SR. Sleep duration and circulating adipokine levels. Sleep. 2011;34(2):147-152.

139. Fornadi K, Lindner A, Czira ME, et al. Lack of association between objectively assessed sleep disorders and inflammatory markers among kidney transplant recipients. Int Urol Nephrol. 2012;44(2):607-617.

140. Tuomilehto H, Peltonen M, Partinen M, et al. Sleep duration, lifestyle intervention, and incidence of type 2 diabetes in impaired glucose tolerance: The Finnish Diabetes Prevention Study. Diabetes Care. 2009;32(11):1965-1971.

141. Pradhan AD, Manson JE, Rifai N, Buring JE, Ridker PM. C-reactive protein, interleukin 6 , and risk of developing type 2 diabetes mellitus. JAMA. 2001;286(3):327-334.

142. Wee CC, Mukamal KJ, Huang A, Davis RB, McCarthy EP, Mittleman MA. Obesity and C-reactive protein levels among white, black, and hispanic US adults. Obesity (Silver Spring). 2008;16(4):875-880.

143. Ford ES, Giles WH, Myers GL, Mannino DM. Population distribution of high-sensitivity C-reactive protein among US men: findings from National Health and Nutrition Examination Survey 1999-2000. Clin Chem. 2003;49(4):686-690.

144. Matthews KA, Sowers MF, Derby CA, et al. Ethnic differences in cardiovascular risk factor burden among middle-aged women: Study of Women's Health Across the Nation (SWAN). Am Heart J. 2005;149(6):1066-1073.

145. Mensah GA, Mokdad AH, Ford ES, Greenlund KJ, Croft JB. State of disparities in cardiovascular health in the United States. Circulation. 2005;111(10):1233-1241.

146. Mensah GA. Eliminating disparities in cardiovascular health: six strategic imperatives and a framework for action. Circulation. 2005;111(10):1332-1336.

147. Chien KL, Chen PC, Hsu HC, et al. Habitual sleep duration and insomnia and the risk of cardiovascular events and all-cause death: Report from a community-based cohort. Sleep. 2010;33(2):177-184.

148. Simpson NS, Banks S, Arroyo S, Dinges DF. Effects of sleep restriction on adiponectin levels in healthy men and women. Physiol Behav. 2010;101(5):693-698.

149. Grandner MA, Patel NP, Gehrman PR, et al. Who gets the best sleep? Ethnic and socioeconomic factors related to sleep disturbance. Sleep Med. 2010;11:470-479. 
150. Friedman EM. Sleep quality, social well-being, gender, and inflammation: an integrative analysis in a national sample. Ann NY Acad Sci. 2011;1231:23-34.

151. Okun ML, Reynolds CF 3rd, Buysse DJ, et al. Sleep variability, healthrelated practices, and inflammatory markers in a community dwelling sample of older adults. Psychosom Med. 2011;73(2):142-150.

152. Chen HY, Cheng IC, Pan YJ, et al. Cognitive-behavioral therapy for sleep disturbance decreases inflammatory cytokines and oxidative stress in hemodialysis patients. Kidney Int. 2011;80(4):415-422.

153. Christakis NA, Fowler JH. The spread of obesity in a large social network over 32 years. $N$ Engl J Med. 2007;357(4):370-379.

154. Suarez EC, Lewis JG, Kuhn C. The relation of aggression, hostility, and anger to lipopolysaccharide-stimulated tumor necrosis factor (TNF)-alpha by blood monocytes from normal men. Brain Behav Immun. 2002;16(6):675-684.

155. Ebrahim IO, Shapiro CM, Williams AJ, Fenwick PB. Alcohol and sleep I: effects on normal sleep. Alcohol Clin Exp Res. 2013;37(4): 539-549.

156. Roehrs T, Papineau K, Rosenthal L, Roth T. Ethanol as a hypnotic in insomniacs: self administration and effects on sleep and mood. Neuropsychopharmacology. 1999;20(3):279-286.

157. Volpato S, Pahor M, Ferrucci L, et al. Relationship of alcohol intake with inflammatory markers and plasminogen activator inhibitor-1 in well-functioning older adults: the Health, Aging, and Body Composition study. Circulation. 2004;109(5):607-612.

158. Kita T, Yoshioka E, Satoh H, et al. Short sleep duration and poor sleep quality increase the risk of diabetes in Japanese workers with no family history of diabetes. Diabetes Care. 2012;35(2):313-318.

159. HeY, Jones CR, Fujiki N, et al. The transcriptional repressor DEC2 regulates sleep length in mammals. Science. 2009;325(5942):866-870.

160. Gottlieb DJ, O'Connor GT, Wilk JB. Genome-wide association of sleep and circadian phenotypes. BMC Med Genet. 2007; 8 Suppl 1:S9.

161. Kim SJ, Lee SK, Kim SH, et al. Genetic association of short sleep duration with hypertension incidence. Circ J. 2012;76(4):907-913.

162. Kuna ST, Maislin G, Pack FM, et al. Heritability of performance deficit accumulation during acute sleep deprivation in twins. Sleep. 2012;35(9):1223-1233.

163. Vgontzas AN, Tsigos C, Bixler EO, et al. Chronic insomnia and activity of the stress system: a preliminary study. $J$ Psychosom Res. 1998;45(1):21-31.
164. Vgontzas AN, Bixler EO, Lin HM, et al. Chronic insomnia is associated with nyctohemeral activation of the hypothalamicpituitary-adrenal axis: clinical implications. J Clin Endocrinol Metab. 2001;86(8):3787-3794.

165. Vgontzas AN, Liao D, Bixler EO, Chrousos GP, Vela-Bueno A. Insomnia with objective short sleep duration is associated with a high risk for hypertension. Sleep. 2009;32(4):491-497.

166. Vgontzas AN, Liao D, Pejovic S, Calhoun S, Karataraki M, Bixler EO. Insomnia with objective short sleep duration is associated with type 2 diabetes: A population-based study. Diabetes Care. 2009;32(11): 1980-1985.

167. Fernandez-Mendoza J, Calhoun S, Bixler EO, et al. Insomnia with objective short sleep duration is associated with deficits in neuropsychological performance: a general population study. Sleep. 2010;33(4): 459-465.

168. Vgontzas AN, Liao D, Pejovic S, et al. Insomnia with short sleep duration and mortality: the Penn State cohort. Sleep. 2010;33(9): $1159-1164$.

169. Gozal D, Serpero LD, Kheirandish-Gozal L, Capdevila OS, Khalyfa A, Tauman R. Sleep measures and morning plasma TNFalpha levels in children with sleep-disordered breathing. Sleep. 2010;33(3):319-325.

170. Khalyfa A, Serpero LD, Kheirandish-Gozal L, Capdevila OS, Gozal D. TNF-alpha gene polymorphisms and excessive daytime sleepiness in pediatric obstructive sleep apnea. J Pediatr. 2011;158(1):81-86.

171. Jean-Louis G, Magai CM, Cohen CI, et al. Ethnic differences in selfreported sleep problems in older adults. Sleep. 2001;24(8):926-933.

172. Knutson KL. Association between sleep duration and body size differs among three Hispanic groups. Am J Hum Biol. 2011;23(1):138-141

173. Loredo JS, Soler X, Bardwell W, Ancoli-Israel S, Dimsdale JE, Palinkas LA. Sleep health in US. Hispanic population. Sleep. 2010;33(7):962-967.

174. Hale L, Rivero-Fuentes E. Negative acculturation in sleep duration among Mexican Immigrants and Mexican Americans. J Immigr Minor Health. 2011;13(2):402-407.

175. Grandner MA, Patel NP, Jean-Louis G, et al. Sleep-related behaviors and beliefs associated with race/ethnicity in women. J Natl Med Assoc. In press 2013.
Nature and Science of Sleep

\section{Publish your work in this journal}

Nature and Science of Sleep is an international, peer-reviewed, open access journal covering all aspects of sleep science and sleep medicine, including the neurophysiology and functions of sleep, the genetics of sleep, sleep and society, biological rhythms, dreaming, sleep disorders and therapy, and strategies to optimize healthy sleep. The journal welcomes

\section{Dovepress}

original research, clinical \& epidemiological studies, reviews \& evaluations, case reports and extended reports. The manuscript management system is completely online and includes a very quick and fair peerreview system, which is all easy to use. Visit http://www.dovepress.com/ testimonials.php to read real quotes from published authors. 